anaesthetic agents in the U.K. or the relative frequency of use of various anaesthetic agents in patients subjected to repeated surgery. Without such information the committee is not in a position to assert that "multiple exposure to halothane carries a relatively greater risk than single exposure."

There is no lack of evidence to suggest that the various risks incurred in attempting a less appropriate technique may well, in aggregate, be a much more serious hazard to patients. It would be a remarkable practitioner indeed, however, who could successfully marshal this evidence and relate it to a partioular instance in the coroner's court in the face of the committee's letter.

We believe that the committee has done a potentially grave disservice to patients in this country by taking this topic out of the realms of scientific debate and emphasizing one unconfirmed and largely irrelevant aspect of the evidence. It is to be hoped that the committee will shortly distribute widely a letter drawing attention to contrary evidence which has now been reported.-We are, etc.,

Michael P. Coplans Chairman, E. B. LEWIS Vice-chairman, C.C.H.M.S. Anaesthetists' Subcommittee Lonjon W.C.2 1 Sherlock, S., Proceedings of the Royal Society
of Medicine, 1964, 57, 305.

SIR,-Dr. W. H. W. Inman and Professor W. W. Mushin (5 January, p. 5) are justified in concluding that their data are consistent with the view that repeated exposure to halothane may increase the incidence of jaundice. However, before allowing this report to influence their clinical judgement anaesthetists should consider certain relevant factors.

Firstly, every chemical agent with proven pharmacological properties also has untoward effects under certain conditions. Thus in order to decide whether or not he will use such an agent the clinician should be able to estimate the risk in broad mathematical terms of a specific untoward effect developing in an individual patient and to balance this risk against the danger to the patient if the drug is not given. In this respect all inhalation anaesthetics carry risks, some of which are of a much more immediate nature than jaundice.

Secondly, the cases of jaundice described in this paper are probably multifactorial in origin, and though halothane may have played a casual role the fact is that only 130 cases have been reported in nine years in a country where halothane must have been administered millions of times over the same period. Accordingly it must be assumed that the role of halothane in provoking jaundice is relatively very small. In this connexion Dr. Inman and Professor Mushin themselves estimate that the risk of jaundice among patients exposed to halothane more than once within a four-week period seems to lie between 1 in 6,000 and 1 in 20,000. In addition it needs to be known what proportion of all surgical patients have more than one anaesthetic in four weeks.

Thirdly, although Dr. Inman and Professor Mushin admit the possibility that other agents when administered repeatedly might be responsible for cases of jaundice, they imply that this is not so since no reports have been received by the Committee on Safety of Medicines. However, whether or not suah cases have been reported they have occurred, as witnessed by the discussion on halothane and hepatitis held in February 1972 at the Royal Society of Medicine. It is not good enough for investigators to ignore evidence because it has not been reported to their particular committee. Furthermore, those of us who practised anaesthesia before the introduction of halothane are well aware that jaundice after successive anaesthetics is no new phenomenon.

In our opinion all investigators in this field have a responsibility to compare the risk of a patient developing jaundice after halothane with the risk of other complication with different agents. This has yet to be done. Thus the circular letter to doctors from the Committee on Safety of Medicines about jaundice following repeated exposure to halothane is singularly unhelpful and is already causing anxiety, especially among registrars, because of the possible medicolegal implications. This is unfortunate. The law very properly takes official documents seriously and official bodies should therefore be careful about the documents that they circulate. We must reiterate that clinical decisions based on medicolegal considerations are not always to the best advantage of our patients, and we believe that anaesthetists are entitled to expect a greater degree of responsibility on the part of those concerned.-We are, etc.,

FIONA ACHESON J. P. PAYNE

St. Peter's Hospitals and Research

Department of Anaesthetics,

Royal College of Surgeons,

ROY M. ACHESON

London School of Hygiene and Tropical Medicine,

London W.C.1 1 Simpson, B. R., and Strunin, L., Proceedings of

\section{Sensitivity of Haemophilus influenzae to Cephalosporins}

SIR,-The survey reported by Dr. J. D. Williams and Mr. J. Andrews (26 January, p. 134) on the sensitivity of Haemophilus influenzae to 15 antibacterial agents provides clinicians and microbiologists with an accessible source of strictly comparable data. In particular, the report impressively confirms the existence of wide variations in the activity of different cephalosporins. However in an otherwise comprehensive review of cephalosporin activity, cephradine receives only passing mention. This aritibiotic has been available for over a year and is of special interest for two reasons. It can be administered either orally or parenterally and apparently only $6 \%$ of it is bound to serum proteins at a concentration of $12 \mu \mathrm{g} / \mathrm{ml}$. Against $H$. influenzae of the highly virulent Pittman serotype b I have found, throughout the past year, that the minimum inhibitory concentration (M.I.C.) of cephradine was consistently below $1 \mu \mathrm{g} / \mathrm{ml}$, while the minimum bactericidal concentration (M.B.C.) was less than $2 \mu \mathrm{g} / \mathrm{ml}$ similar results have also been obtained elsewhere. ${ }^{2}$ The relatively avirulent non- capsulate strains appear to be generally less sensitive than type b strains, though all M.B.C.s have been within the range of readily attainable serum concentrations of the antibiotic.

Unfortunately Dr. Williams and Mr. Andrews do not mention which types of $H$. influenzae they included in their survey, nor do they provide M.B.C. data. Also, their inoculum of 1,000 bacteria for each test is approximately one-hundredth of the customary inoculum for this delicate organism. It is surprising, too, that in quoting blood levels for the other orally available cephalosporin, cephalexin, they refer only to a 250$\mathrm{mg}$ dose, whereas in the case of the remaining cephalosporins and indeed of most of the other antibiotics the blood levels they quote were obtained after more realistic $500-\mathrm{mg}$ or $1-\mathrm{g}$ doses. The satisfactory blood levels obtained after a 500-mg dose of any of the available cephalosporins, together with the low serum binding of cephradine and its evident activity against $\boldsymbol{H}$. influenzae, would appear to cast doubt on the statement of Dr. Williams and Mr. Andrews that "the oral cephalosporins are not indicated" in haemophilus infections.-I am, etc.,

Westminster Medical School,

SYDNEY SELWYN London S.W.1

1 Neiss, E. S., Fournal of the Irish Medical Asso-

2 ciation, 1973, 66, no. 6 (Suppl.), p.

\section{Medical Audit}

SIR,-While recognizing that medical auditing is applicable mainly to some technical aspects of medical care and to patients with specified conditions, Dr. P. J. Sanazaro (16 February, p. 271) advocates its use as a method for evaluating the quality of care provided by hospitals. A committee of the hospital medical staff first has to define essential criteria for specific diagnoses, conditions, or procedures. Then, after review and approval of the criteria by the entire medical staff, lay staff are authorized to examine the patients' hospital records for discrepancies between the recorded information and the relevant criteria. With this dossier the audit committee pronounces on any professional inadequacies that come to light and recommends appropriate medical education or "discussion" with the medical staff or head of a department as a prelude to subsequent re-auditing.

Essential criteria are defined as those elements of diagnosis and treatment which are essential to the proper care of every patient with a specified condition, and assessments are made from the records of the case history, physical examination, laboratory and radiological procedures, and from the treatment that has been prescribed. Dr. Sanazaro realizes that medical auditing based on present-day records may have serious limitations because, for one or more reasons, such records are often incomplete. To overcome the deficiency he recommends adoption of standardized forms for use in general and in outpatient practice. There is much merit in the use of a standard form for recording the case history, clinical examination, and ancillary studies provided it is possible to include a written account of the patient's own pertinent comments regarding his illness 